\title{
Improving the accuracy of a fluid transport method
}

\author{
A. R. Özok ${ }^{1}$, B. Verhaagen ${ }^{2} \&$ P. R. Wesselink ${ }^{1}$ \\ ${ }^{1}$ Department of Conservative and Preventive Dentistry, Academic Centre for Dentistry Amsterdam (ACTA), University of \\ Amsterdam and VU University Amsterdam, Amsterdam, The Netherlands; and ${ }^{2}$ Physics of Fluids Group Faculty of Science and \\ Technology MIRA Institute for Biomedical Technology and Technical Medicine, University of Twente, Enschede, The \\ Netherlands
}

\section{Abstract}

Özok AR, Verhaagen B, Wesselink PR. Improving the accuracy of a fluid transport method. International Endodontic Journal, 46, 348-354, 2013.

Aim To compare the sealing ability of the same root fillings when measured by a conventional fluid transport method that uses water or by a modified fluid transport method that uses a wetting fluid as tracer.

Methodology The amount of fluid transport along the same root fillings (AH26, cold lateral compaction of gutta-percha) was measured in a cross-over design in fluid transport set-ups using either water or a wetting fluid as tracer.
Results A Wilcoxon signed-rank test revealed a significant difference in the amount of fluid transport measured along the same root fillings by the two fluid transport methods $(P=0.013)$. The fluid transport method using wetting fluid detected a significantly higher percentage of root fillings with fluid transport $(P=0.021)$.

Conclusions Fluid transport using a wetting fluid as a tracer was more sensitive in the assessment of sealing ability of root fillings than the conventional fluid transport method using water.

Keywords: fluid transport, root canal filling material, sealing ability, wetting fluid.

Received 30 May 2011; accepted 3 August 2012

\section{Introduction}

The fluid transport experimental model, a well-established method, has been widely used to measure the sealing ability of various root filling materials (Pashley 1990, Wu et al. 1993) ex vivo. However, the clinical relevance of sealing ability tests has been questioned (editorial JOE 2007). To reveal a possible clinical relevance, a combination of a diagnostic tool to accurately screen the periapical status of a rootfilled tooth, such as 3-dimensional cone beam computed tomography scans (Estrella et al. 2008), and an

Correspondence: A. R. Özok, Department of Conservative and Preventive Dentistry, Academic Centre for Dentistry Amsterdam (ACTA), University of Amsterdam and VU University Amsterdam, Mahlerlaan 3004, 1081 LA Amsterdam, The Netherlands (e-mail: r.ozok@acta.nl). accurate method to measure its ex vivo sealing ability is required.

Various methods have been developed to measure the ex vivo sealing ability of a root filling, each with its limitations. A vast majority of the studies used linear dye penetration, whilst others used electrochemical techniques, capillary flow porometry or the penetration of other tracers, mainly bacteria or bacterial toxins (ex vivo microbial leakage method) or glucose (de Bruyne et al. 2005a). The reactivity of several root filling materials with glucose is a limitation of this tracer (Shemesh et al. 2008). The lack of adequate negative controls, a potential systematic error, in ex vivo experiments on microbial leakage, has been elegantly described and discussed elsewhere (Rechenberg et al. 2011). In an ex vivo study, the sealing ability in the same root-filled teeth was measured consecutively using fluid transport, electrochemical and linear dye penetration methods (Pommel et al. 2001). Whilst the fluid transport and 
linear dye penetration methods revealed differences regarding sealing ability between various filling techniques, the electrochemical technique was unable to reveal any differences (Pommel et al. 2001).

Several studies have attempted to disclose a possible correlation between the ex vivo sealing ability of rootfilled teeth and so-called 'clinical success' (Oliver \& Abbott 2001) or the presence/absence of periapical lesions (Susini et al. 2006). They were unable to detect any such correlation. Perhaps such a correlation does not exist, but it is also possible that a correlation does exist, and that the studies used methods that were not sufficiently accurate. The study that aimed to disclose a correlation between 'clinical success' and ex vivo sealing ability (Oliver \& Abbott 2001) used linear methylene blue penetration methods in combination with a vacuum. The inhibition of dye penetration because of entrapped air at the filling-dentine interface is a major shortcoming of linear dye penetration (Spångberg et al. 1989, Wu et al. 1994), and combining it with vacuum has been shown to be effective (Kazemi \& Spångberg 1995). However, other flaws of dye penetration methods include decolouration of the dye in contact with a number of the root filling materials ( $\mathrm{Wu}$ et al. 1998), being destructive for the sample, and the possibility that linear dye penetration may be lost or remain undetected after horizontal sectioning of the roots (Tamse et al. 1998, Camps \& Pashley 2003). A modification of the dye penetration method, dye extraction (Douglas \& Zakariasen 1981), uses nitric acid to dissolve the roots after dye penetration to extract the tracer. This method is also destructive but has been shown to produce comparable results as conventional fluid transport method (Camps \& Pashley 2003). Susini et al. (2006) used a dye extraction method to evaluate ex vivo sealing ability in combination with two-dimensional periapical radiographs to assess periapical status. Although they reported significantly greater apical dye penetration in teeth with 'visibly' poor root fillings than in teeth with good root fillings, they were unable to detect any significant correlation between apical dye penetration and the presence of a periapical radiolucency. If they had used a more sensitive method to assess the ex vivo sealing ability and cone-beam computed tomography scans to check the periapical status, their findings might have been different.

In the present study, a quantitative, nondestructive, reliable, reproducible and well-established sealing ability method with improved sensitivity is presented. The principle of fluid transport tests is that the fluid penetrates into through-and-through voids within or between the filling material and the dentine wall in a root canal, and under pressure, it starts to flow (Wu et al. 1993). This fluid flux leads to a displacement of an air bubble inside a connected glass capillary tube. By recording the linear displacement of the air bubble, the amount of leakage (in volume/time) can be measured. Water has been the tracer fluid in fluid transport set-ups. The relatively high surface tension of water, however, can introduce a limitation in sealing ability measurements. Whilst at $25^{\circ} \mathrm{C}$ the surface tension of water is $72 \mathrm{mN} \mathrm{m}^{-1}$ (Sovanna et al. 2009), that of ethyl alcohol is only $22 \mathrm{mN} \mathrm{m}^{-1}$. A low surface tension means that the fluid can penetrate into the voids, even the smallest ones, more easily. This may lead to the detection of smaller voids, and thus, a more sensitive measurement of the sealing ability of a filling material. The capillary flow porometry method uses a wetting fluid and has been shown to be more sensitive than conventional fluid transport methods (de Bruyne et al. 2005b, 2006). However, the relatively high pressure needed for this technique may be a drawback in the sealing ability measurement of some root filling materials.

The null hypothesis is that measurement of the sealing ability of a root filling material with the use of a fluid transport set-up using either water or wetting fluid, which has a lower surface tension than water, yields similar results. For this purpose, fluid transport was measured along the same root fillings using water or a wetting fluid as tracer.

\section{Material and methods}

Thirty extracted human mandibular premolars with a single root and canal were selected. The teeth were then distributed randomly amongst the experimental groups 1 and $2(n=2 \times 10)$, negative $(n=10)$ and positive $(n=5)$ control groups.

\section{Preparation of the specimens}

The specimens were prepared as described previously (Ozok et al. 2008). Briefly, the teeth were embedded in self-polymerizing methyl methacrylate resin cylinders (Dentimex, Zeist, the Netherlands), leaving the apical one-third of the root uncovered, and were decoronated $14 \mathrm{~mm}$ from the apex. The margins adjoining the root and resin were sealed with cyanoacrylate glue (Permacol, Ede, the Netherlands). Except for the 
apical foramen and the coronal access, the entire specimen surface was covered with two layers of nail varnish. In the negative controls, the whole surface was covered.

\section{Instrumentation of the root canals}

A size $15 \mathrm{~K}$-file was inserted in the root canal until it was just visible at the apical foramen. The root canals were prepared $1 \mathrm{~mm}$ short of this length using GTrotary instruments (Dentsply Maillefer, Ballaigues, Switzerland) to a 0.06 taper master apical size of 30 . After each instrument size, canals were rinsed with $2 \mathrm{~mL} 2 \%$ sodium hypochlorite $(\mathrm{NaOCl})$. After completion of the preparations, the canals were also rinsed with $2 \mathrm{~mL} 2 \% \mathrm{NaOCl}$, a size $15 \mathrm{~K}$-file was inserted in the root canal, and the remaining irrigant was activated ultrasonically (P5-Suprasson; Satelec, Merignac, France) for $1 \mathrm{~min}$. The canals were then flushed with $0.5 \mathrm{~mL} 17 \%$ EDTA solution, which was left in place for $1 \mathrm{~min}$. Subsequently, the canals were rinsed with $2 \mathrm{~mL} \mathrm{NaOCl}$, deionised water and $80 \%$ ethanol, respectively, and dried with paper points. The patency of the apical foramen was confirmed by inserting the tip of a size 15 file through it.

\section{Filling of the root canals}

The root canals were filled with AH26 (Dentsply DeTrey, Konstanz, Germany) in combination with lateral compaction of gutta-percha cones (Henry Schein, Gillingham, UK). AH26 paste was mixed according to the manufacturer's recommendations. A lentulo spiral was swiped through the AH26 paste once, and inserted into the root canal at working length. A size 30 gutta-percha master cone was lightly coated with the AH26 paste, and inserted into the canal to working length. With the use of a size $\mathrm{B}$ spreader and 8 -10 size 25 gutta-percha cones, the root canals were filled.

Root canals $(n=5)$ filled with no sealer and loosely fitting gutta-percha cones served as positive controls. Root canals that were filled in the same manner as described above were completely sealed with nail varnish (including the apical foramen and the coronal access) to serve as negative controls.

\section{The wetting fluid}

The wetting fluid Galpore (Benelux Scientific, Eke, Belgium) used in the present study has been used in sealing ability tests by capillary flow porometry (De Bruyne et al. 2005b, 2006). This very stable and nonreactive wetting fluid, which has a low vapour pressure $(3.33 \mathrm{~Pa})$ and low surface tension $\left(19 \mathrm{mN} \mathrm{m}^{-1}\right)$ is a perfluoroether polymer with a viscosity of $4.4 \mathrm{mPa}$.s.

\section{Measurement of fluid transport}

A modified fluid transport set-up described by $\mathrm{Wu}$ et al. (1993) operating at $0.05 \mathrm{MPa}$ either using water or a wetting fluid as tracer was used.

The fluid transport measurements were performed in a cross-over design. The fluid transport in samples in group 1 was first measured in a conventional fluid transport set-up, then in a wetting fluid set-up. The measurements in group 2 were made in a wetting fluid set-up, then in a conventional set-up. The replacement of the air bubble was recorded by two independent observers.

Assembly of and measurements in the conventional set-up were performed in a water bath at room temperature. Assembly of and measurements in the wetting fluid set-up were performed in the open air, in ventilated chambers, wearing gloves and goggles at all times.

The measurement time has an influence on the amount of fluid transport observed. A reduction in fluid transport with an increased measurement time has been reported (Pommel \& Camps 2001). In the present study, the fluid transport measurements were performed at 1,3 and $6 \mathrm{~h}$. As a repeated-measures ANOVA test revealed no significant differences regarding fluid transport (no change in case of measurements with water) between the time intervals $(P>0.05$; data not shown), the data for $1 \mathrm{~h}$ is presented. This shorter measurement time is also considered to be an improvement of the fluid transport model.

\section{Statistical analysis}

Data were analysed on SPSS 16.0 software for Windows (SPSS Benelux, Gorinchem, the Netherlands). The effect of the sequence of the measurements was analysed using a Fisher's exact test. The pair-wise comparison was performed with a Wilcoxon signedrank test. The comparison between the groups, of the percentages of the root canal fillings showing fluid transport, was performed using a McNemar's test. Values of $P<0.05$ were considered as statistically significant. 


\section{Results}

No fluid transport was measured in the negative control groups (both fluid transport set-ups) for $1 \mathrm{~h}$. The replacement of the air bubble in the positive controls was too rapid to be recorded.

The distribution amongst the groups 1 (water first, wetting fluid second; $n=10$ ) and 2 (wetting fluid first, water second; $n=10$ ) of the fluid transport values in the same root canal fillings measured in a fluid transport set-up using either water or a wetting fluid as a tracer in a cross-over design is shown in Table 1. As the effect of the sequence of the measurements (the cross-over design) was not statistically significant $(P>0.05)$, the values were pooled $(n=20)$ in Table 2 .

Table 1 The distribution among the groups $(n=10)$ of the fluid transport values (range $0-2 \mu \mathrm{L} \mathrm{h}^{-1}$ ) in the same root canal filling measured in a fluid transport set-up using either water or a wetting fluid as a tracer in a cross-over design. Since the effect of the sequence of the measurements was not statistically significant $\left(\chi^{2}\right.$ test $\left.P>0.05\right)$, the values were pooled in Table 2

\begin{tabular}{|c|c|c|c|c|}
\hline & \multicolumn{4}{|c|}{ Wetting fluid first $\left(\mu \mathrm{L}^{-1}\right)$} \\
\hline & 0 & 1 & 2 & Total \\
\hline \multicolumn{5}{|c|}{$\begin{array}{l}\text { Water second } \\
\left(\mu \mathrm{L} \mathrm{h}^{-1}\right)\end{array}$} \\
\hline 0 & 4 & 3 & 2 & 9 \\
\hline 1 & 1 & 0 & 0 & 1 \\
\hline 2 & 0 & 0 & 0 & 0 \\
\hline \multirow[t]{3}{*}{ Total } & 5 & 3 & 2 & 10 \\
\hline & \multicolumn{4}{|c|}{ Wetting fluid second $\left(\mu \mathrm{L} \mathrm{h}^{-1}\right)$} \\
\hline & 0 & 1 & 2 & Total \\
\hline \multicolumn{5}{|c|}{$\begin{array}{c}\text { Water first } \\
\left(\mu \mathrm{L} \mathrm{h}^{-1)}\right.\end{array}$} \\
\hline 0 & 6 & 4 & 0 & 10 \\
\hline 1 & 0 & 0 & 0 & 0 \\
\hline 2 & 0 & 0 & 0 & 0 \\
\hline Total & 6 & 4 & 0 & 10 \\
\hline
\end{tabular}

Table 2 The distribution among the groups $(n=20)$ of the fluid transport values (range $0-2 \mu \mathrm{L} \mathrm{h}^{-1}$ ) in the same root canal filling measured in a fluid transport set-up using either water or a wetting fluid as a tracer

\begin{tabular}{lrccr}
\hline & \multicolumn{4}{c}{ Wetting fluid $\left(\mu \mathrm{L} \mathrm{h}^{-1}\right)$} \\
\cline { 2 - 5 } & 0 & 1 & 2 & Total \\
\hline Water $\left(\mu \mathrm{L} \mathrm{h}^{-1}\right)$ & & & & \\
0 & 10 & 7 & 2 & 19 \\
1 & 1 & 0 & 0 & 1 \\
2 & 0 & 0 & 0 & 0 \\
Total & 11 & 7 & 2 & 20 \\
\hline
\end{tabular}

The mean (SD) fluid transport measured in the same root canals was $0.05(0.22) \mu \mathrm{L} \mathrm{h}^{-1}$ with water and 0.55 (0.69) $\mu \mathrm{L} \mathrm{h}^{-1}$ with wetting fluid (Fig. 1a), and this difference was statistically significant $(P=0.013)$.

The percentage of root canals showing fluid transport was 0.05 with water and 0.45 with wetting fluid (Fig. 1b). The difference between the two fluid transport set-ups regarding the percentage of samples showing fluid transport was statistically significant $(P=0.021)$.

\section{Discussion}

The increase in sensitivity when using the wetting fluid instead of water can be explained using the theory for capillary flow. It is assumed that there are open cavities within and between the root canal filling and dentine wall. These cavities are filled with air, which has to be removed before any flow can take place through the cavities. When more cavities become 'open' (no air entrapped), the fluid flow through the filled root canal will increase and more 'leakage' will be detected (Hernández et al. 1996).

The cavity can be modelled as a cylindrical capillary of diameter $d$, in which the applied pressure $P_{\mathrm{a}}$ should overcome the Laplace (capillary) pressure $P_{\mathrm{c}}$ of the entrapped air (Bechhold et al. 1931) to push the air out of the capillary. The Laplace pressure is given by the following equation (De Gennes et al. 2004):

$$
P_{\mathrm{c}}=\frac{4 \sigma \cos \theta}{d}
$$

Here, $\sigma$ is the surface tension of the liquid-air interface and $\theta$ the wetting angle with dentin. Equation (1) can be rewritten to:

$$
d=\frac{4 \sigma \cos \theta}{P_{\mathrm{c}}}
$$

showing that, at a specific applied pressure $\left(P_{\mathrm{a}}=P_{\mathrm{c}}\right)$, the minimum capillary (or pore) diameter from which the air can be removed, is linearly related to the surface tension of the fluid.

Whilst under a pressure of $0.13 \mathrm{MPa}$, the smallest pore that can be filled with water is one with a diameter of $1.4 \mu \mathrm{m}$ [for water $\sigma=72 \mathrm{mN} \mathrm{m}^{-1}, \theta=50^{\circ}$ (Wu \& Nancollas 1997)], the wetting fluid as used in this study $\left[\sigma=19 \mathrm{mN} \mathrm{m}^{-1}, \theta=50^{\circ}\right.$ (assumption, see below)] can fill pores with a diameter of $0.4 \mu \mathrm{m}$. The contact angle for the wetting fluid on dentine is 

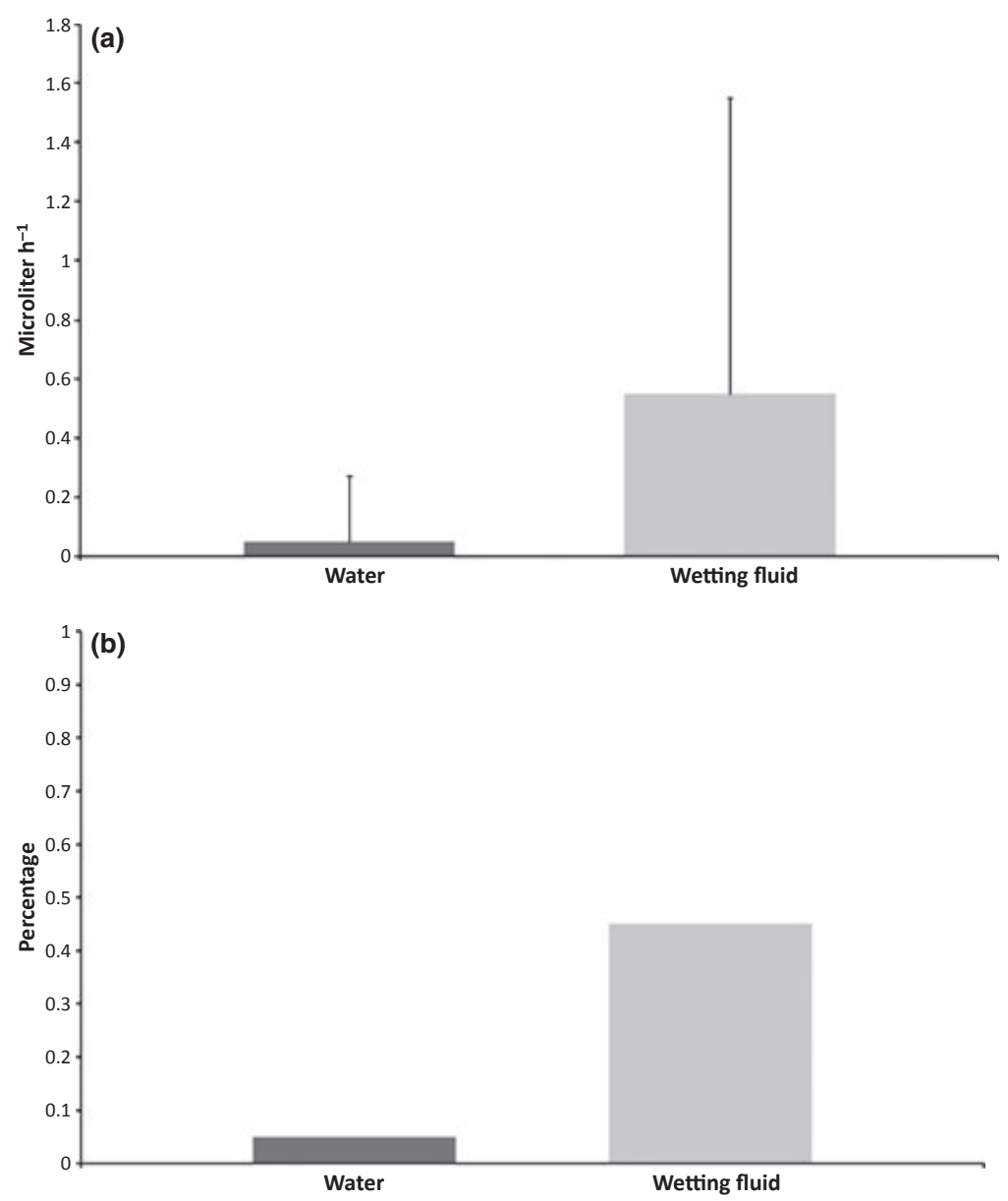

Figure 1 The mean (SD) fluid transport measured in the same root canal fillings in $\mu \mathrm{L} \mathrm{h}^{-1}$ (a). The percentage of root canal fillings that showed fluid transport (b). not known, but its influence is limited. When the contact angle is smaller than $50^{\circ}$, the minimum pore diameter would be $0.6 \mu \mathrm{m}$ at most, whereas when it is larger than $50^{\circ}$, the minimum pore diameter would be even smaller than $0.4 \mu \mathrm{m}$.

In this study, significantly more fluid transport was detected using the wetting fluid than with water after $1 \mathrm{~h}$. Besides, the only root filling that showed fluid transport when water was used as tracer was previously used in a fluid transport set-up using wetting fluid as tracer in the cross-over design. It can be speculated that many small pores, which have been opened with the wetting fluid will all contribute to the total flow through the filled root. However, the flow rate through a porous medium is also determined by the viscosity of the fluid, which is 4.4 times higher for the wetting fluid (4.4 mPa.s) than for water (1.0 mPa.s). Darcy's Law (Nield \& Bejan 1999) for liquid flow through a porous medium predicts that the flow rate is inversely proportional to the viscosity and should go down by a factor of 4.4 when using the wetting fluid instead of water. However, the significant increase in flow rate that is measured suggests that the pores were filled with air; therefore, capillary flow is applicable here. Washburn's Law (Washburn 1921) for purely capillary flow predicts that the flow rate through the pores is related to the ratio of surface tension to viscosity $(\sigma / \eta)$, which is approximately equal for wetting fluid and water.

Not only the air in the pores will be removed more easily by the wetting fluid, but the bubble in the capillary tube that is used to monitor the fluid transport is also affected by the wetting fluid. The change in surface tension with wetting fluid will decrease the Laplace pressure inside this bubble and make it easier to be displaced.

It can be speculated that the solubility of air into the wetting fluid may also contribute to the increase in sensitivity. This value is not known, but it is possible that air dissolves into the wetting fluid at a higher 
rate than into water, leading to a more rapid removal of air from the pores.

The wetting fluid used in the present study has been used in sealing ability tests by capillary flow porometry (De Bruyne et al. 2005b, 2006). Capillary flow porometry was significantly more sensitive in detecting through-and-through voids along the root canal filling than conventional fluid transport (De Bruyne et al. 2005b). The pressure used by capillary flow porometry, however, can reach $1.4 \mathrm{MPa}$. This amount of pressure may be destructive for many of root filling materials, especially on their adhesion to the root canal wall (Jainaen et al. 2007, Carneiro et al. 2012). The use of a wetting fluid in combination with the fluid transport set-up does not necessitate the use of high pressures. The advantage of the current method is the improvement in the sensitivity of the fluid transport without creating possible artefacts because of the use of relatively high pressures, as may be the case in capillary flow porometry.

One may question the importance of detecting the smallest through-and-through voids. Some of these voids can be so small that only low surface tension fluids, such as the wetting fluid can penetrate but they may not be accessible for bacteria or their by-products. Various bacterial by-products (lipopeptides, glycolipids, lipopolysaccharides, lipoproteins) are amphiphilic molecules (Banat et al. 2000), which may behave as surfactants or emulsifiers that can lower the interfacial tension between a liquid and a solid surface (Banat et al. 2000, 2010, Singh et al. 2005). Surfactants can reduce surface tension and change water into a wetting fluid (Singh et al. 2005). This may mean that the wetting fluid is a more suitable tracer to mimic bacterial by-products than water. It is also very probable that lipopolysaccharides owing to their rather small molecular size $(10 \mathrm{kDa}$; Lerouge \& Vanderleyden 2011) may fit in the smallest voids. Unfortunately, there is no recognized threshold for the size of the void that can be clinically relevant.

\section{Conclusions}

The fluid transport set-up using wetting fluid as a tracer was more accurate in the assessment of sealing ability than the conventional fluid transport set-up. The present findings suggest that fluid transport measured using a conventional model with water was probably an underestimation. Studies using a combination of accurate methods to measure sealing ability and to screen the periapical status are needed to reveal a possible relation between these two phenomena.

\section{Acknowledgements}

We would like to thank J. Snoeijer for his contribution to the manuscript, and I.H.A. Aartman for her contribution to the statistical analysis.

B. Verhaagen is sponsored by the Dutch Technology Foundation (STW) project 07498.

\section{References:}

Banat IM, Makkar RS, Cameotra SS (2000) Potential commercial applications of microbial surfactants. Applied Microbiology and Biotechnology 53, 495-508.

Banat IM, Franzetti A, Gandolfi I et al. (2010) Microbial biosurfactants production, applications and future potential. Applied Microbiology and Biotechnology 87, 427-44.

Bechhold H, Schlesinger M, Silbereisen K (1931) Porenweite von Ultrafiltern. Kolloid Zeitschrift 55, 172-98.

De Bruyne MA, De Bruyne RJ, Rosiers L, De Moor RJ (2005a) Longitudinal study on microleakage of three rootend filling materials by the fluid transport method and by capillary flow porometry. International Endodontic Journal 38, 129-36.

De Bruyne MA, Verhelst PC, De Moor RJ (2005b) Critical analysis of leakage studies in endodontics. Revue Belge Médecine Dentaire 60, 92-106.

De Bruyne MA, De Bruyne RJ, De Moor RJ (2006) Long-term assessment of the seal provided by root-end filling materials in large cavities through capillary flow porometry. International Endodontic Journal 39, 493-501.

Camps J, Pashley DH (2003) Reliability of dye penetration studies. Journal of Endodontics 29, 592-4.

Carneiro SMBS, Sousa-Neto MD, Rached-Júnior FA, Miranda CES, Silva SRC, Silva-Sousa YTC (2012) Push-out strength of root fillings with or without thermomechanical compaction. International Endodontic Journal 45, 821-3.

Douglas WH, Zakariasen U (1981) Volumetric assessment of apical leakage utilizing a spectro-photometric dye recovery method. Journal of Dental Research 60, 438-43.

Editorial (2007) Wanted: a base of evidence Journal of Endodontics 33, 1401.

Estrella C, Bueno MR, Leles CR, Azevedo B, Azevedo JR (2008) Accuracy of Cone Beam Computed Tomography and Panoramic and Periapical Radiography for Detection of Apical Periodontitis. Journal of Endodontics 34, 273-9.

De Gennes P-G, Brochard-Wyart F, Quéré D (2004) Capillary and wetting phenomena, 1st edn. New York: Springer.

Hernández A, Calvo JI, Prádanos P, Tejerina F (1996) Pore size distributions in microporous membranes: a critical analysis of the bubble point extended method. Journal of Membrane Science 112, 1-12. 
Jainaen A, Palamara JE, Messer HH (2007) Push-out bond strengths of the dentine-sealer interface with and without a main cone. International Endodontic Journal 40, 882-90.

Kazemi RB, Spångberg LS (1995) Effect of reduced air pressure on dye penetration in standardized voids. Oral Surgery Oral Medicine Oral Pathology Oral Radiology Endodontics 80, 720-5.

Lerouge I, Vanderleyden J (2011) O-antigen structural variation: mechanisms and possible roles in animal/plantmicrobe interactions. FEMS Microbiology Reviews 26, 17 -47 .

Nield DA, Bejan A (1999) Convection in porous media, 2nd edn. New York: Springer-Verlag.

Oliver CM, Abbott PV (2001) Correlation between clinical success and apical dye penetration. International Endodontic Journal 34, 637-44.

Ozok AR, Sluis LWM, Wu M-K, Wesselink PR (2008) Sealing ability of a new polydimethylsiloxane-based root canal filling material. Journal of Endodontics 34, 204-7.

Pashley DH (1990) Clinical considerations of microleakage. Journal of Endodontics 16, 70-7.

Pommel L, Camps J (2001) Effects of pressure and measurement time on the fluid filtration method in endodontics. Journal of Endodontics 27, 256-8.

Pommel L, Jacquot B, Camps J (2001) Lack of correlation among three methods for evaluation of apical leakage. Journal of Endodontics 27, 347-50.

Rechenberg DK, De-Deus G, Zehnder M (2011) Potential systematic error in laboratory experiments on microbial leakage through filled root canals: review of published articles. International Endodontic Journal 44, 183-94.

Shemesh H, Souza EM, Wu M-K, Wesselink PR (2008) Glucose reactivity with filling materials as a limitation for using the glucose leakage model. International Endodontic Journal 41, 869-72.
Singh A, Van Hamme JD, Ward OP (2005) Surfactants in microbiology and biotechnology: part 2. Application aspects. Biotechnology Advances 25, 99-121.

Sovanna S, Suzuki T, Kojima M, Tachiyashiki S, Kita M (2009) Surface tension reduction (STR) in aqueous solutions of anionic surfactants with cobalt(III) complexes. Journal of Colloid and Interface Science 332 , 194-200.

Spångberg LS, Acierno TG, Yongbum Cha B (1989) Influence of entrapped air on the accuracy of leakage studies using dye penetration methods. Journal of Endodontics $\mathbf{1 5}$, 548-51.

Susini G, Pommel L, About I, Camps J (2006) Lack of correlation between ex vivo apical dye penetration and presence of apical radiolucencies. Oral Surgery Oral Medicine Oral Pathology Oral Radiology Endodontics 102, e19-23.

Tamse A, Katz A, Kablan F (1998) Comparison of apical leakage shown by four different dyes with two evaluating methods. International Endodontic Journal 31, 333-7.

Washburn EW (1921) The dynamics of capillary flow. Physical Review 17, 273-83.

Wu W, Nancollas GH (1997) The relationship between surface free-energy and kinetics in the mineralization and demineralization of dental hard tissue. Advances in Dental Research 11, 566-75.

Wu MK, De Gee AJ, Wesselink PR, Moorer WR (1993) Fluid transport and bacterial penetration along root canal fillings. International Endodontic Journal 26, 203-8.

Wu MK, De Gee AJ, Wesselink PR (1994) Fluid transport and dye penetration along root canal fillings. International Endodontic Journal 27, 233-8.

Wu M-K, Kontakiotis EG, Weselink PR (1998) Decoloration of $1 \%$ methylene blue solution in contact with dental filling materials. Journal of Dentistry 26, 585-9. 